\title{
Influence of Heat Treatment on Residual Stress in Cold-Forged Parts
}

\author{
Frederico Ozanan Neves, Thiago Luis Lara Oliviera, \\ Durval Uchoas Braga, and Alex Sander Chaves da Silva
}

Universidade Federal de São Joao del-Rei, Praça Frei Orlando, 170 Centro, 36307-352 São João del Rei, MG, Brazil

Correspondence should be addressed to Frederico Ozanan Neves; fred@ufsj.edu.br

Received 18 March 2014; Revised 3 September 2014; Accepted 17 September 2014; Published 30 October 2014

Academic Editor: Rui Vilar

Copyright (C) 2014 Frederico Ozanan Neves et al. This is an open access article distributed under the Creative Commons Attribution License, which permits unrestricted use, distribution, and reproduction in any medium, provided the original work is properly cited.

\begin{abstract}
Residual stresses are those stresses that remain in a body when there is no external load applied. Numerous factors can induce residual stresses in the material, including cold forming. Thermal treatments of steel are widely used because they can improve the mechanical properties of the steel, such as toughness, tenacity, and resistance; however, thermal treatments can also produce residual stresses. This study aims to analyze the residual stresses present in a cold-forged part after heat treatments. Half-cylinder samples of AISI 1045 steel were cold-forged, and a wedge tool was pressed into their surface, causing a strain gradient. The samples were then heat-treated by annealing, normalizing, quenching, or quenching and tempering. A numerical simulation was also performed to aid in choosing the measurement points in the samples. The results show that residual stresses are dependent on the heat treatment and on the intensity and nature of previous residual stresses in the body.
\end{abstract}

\section{Introduction}

In the forging process, metal is deformed plastically between two or more dies to give it the desired shape and size. The friction at the die-specimen interface creates nonuniform strain and stress distributions. This inhomogeneity in deformation is manifested in the bulging of the specimen. Another significant consequence of the inhomogeneity is the generation of residual stresses on unloading, as shown by Mungi et al. [1]. Using numerical analysis of an axisymmetric forging process, which was validated by comparison with experimental results from the literature, they showed that there was a region with a high residual stress gradient at the edge of the interface between the tool and the metal piece.

Residual stresses are the stresses remaining in a body when all external forces have been removed. These stresses are a consequence of heat treatment, as has been observed previously. Camurri et al. [2] conducted an experiment to verify the influence of quenching on residual stress in grinding balls. Residual stress results obtained from X-ray diffraction showed good agreement with the results predicted by a numerical model. Lados et al. [3] used a modified quenching method to reduce the residual stress in a cast alloy. The method consisted of a conventional quench followed by an uphill quench. Forming processes are also responsible for introducing residual stress in parts. Martins et al. [4] deformed one region of a stamped valve to introduce compressive residual stress, thereby improving the valve's fatigue strength. Machining is another source of residual stress. Tang et al. [5], for example, studied the influence of tool flank wear on residual stresses in milled parts. They observed that, as the tool flank wear increased, the compressive residual stresses and the part thickness also increased.

In general, the pattern of residual stress will be opposite to the pattern of the plastic strain that produced it. For example, in the case of a rolled sheet, the residual stress pattern consists of a high compressive stress in the surface that was elongated in the longitudinal direction by the rolling process. After the external force has been removed, there is compressive stress at the surface and tensile stress at the center of the sheet. Compressive residual stress is desirable when the part will be submitted to cyclical loads because the residual stress prevents nucleation and the propagation of cracks, reducing the possibility of failure by fatigue. 
Two types of tests are used to measure residual stress: destructive tests and nondestructive tests.

The most common nondestructive tests are based on the relationships between physical parameters measured by Xray or ultrasound. The stress state is determined from the interaction of a monochromatic beam with a polycrystalline material, in which the incident photons diffract as described by Bragg's law, as observed by Meisner et al. [6]. They used this technique to study the residual elastic stresses and microstructure in near-surface layers that had been modified using electron beams. When part of a polycrystalline material has been plastically deformed, a uniform strain results over long sections of the crystalline lattice planes containing crystallites (i.e., grains), which changes the free state to a new state that is dependent on the intensity of the applied stress. This new spacing between the grains (in any group of planes with the same orientation relative to the applied stress) can be measured by X-ray diffraction. Other nondestructive techniques include ultrasonic velocity measurement and Barkhausen noise analysis.

In this work, another technique is used to evaluate residual stress. This technique is based on an indentation test, as described by Wronski et al. [7]. They developed a technique relating residual stress to microhardness. This technique was used by Bocciarelli and Maier [8] to identify and map residual stress; they compared their results with numerical simulations and obtained very good agreement. The method is based on the phenomenon that, in a surface under compressive residual stress, indentation will be difficult and the hardness will be greater than in a surface without residual stress. In the case of tensile residual stress in the surface, indentation will be easier and the hardness will be less than in a surface without residual stress. Consequently, a map of the amount and distribution of residual stress can easily be obtained at low cost, without the need for sophisticated equipment.

Heat treatment of steel parts is widely used to improve the steel's mechanical properties. Often, cold-formed parts are subjected to heat treatment to improve the mechanical properties after the forming process or to eliminate undesirable properties.

There are numerous heat treatments used for steel; the most common are quenching, tempering, normalizing, and annealing. Quenching is used to increase the hardness of the material. Tempering acts to relieve the stresses induced by quenching. Annealing is used to recover cold work and relax the internal stresses, thereby improving formability. Normalizing is generally used to improve the mechanical properties of the material by refining its microstructure. An example of research involving residual stress and heat treatment is the work of Tanner and Robinson [9]. They studied closed-die forgings manufactured from aluminum alloy submitted to standard and nonstandard heat treatments to reduce the as-quenched residual stress magnitude. They concluded that quenching in boiling water results in a very low residual stress; however, it also promotes unsatisfactory mechanical properties.

Koç et al. [10] investigated the possibility of using cold forming to reduce the residual stresses resulting from quenching. In their work, they submitted a quenched part to compression or stretching via a cold process. Their results showed that the level of stress in the part could be reduced by up to $90 \%$.

To reduce expense and time, a factorial design is a good statistical technique to use for experiments. Factorial design allows the experimenter to determine the influence of process factors and analyze their interactions. Grum and Slabe [11] used this technique to investigate and choose the best conditions for heat treatment in Ni-Co-Mo surfaced layers. They recommended its use because of its simplicity and the ease of adapting it to other experimental processes. Another example of the use of statistical techniques to study the influence of process parameters was presented in the work of Grum and Bergant [12]. They used a Taguchi method based on the analysis of variance to determine the optimum method for the flame spraying of NiCrBSi coatings to obtain greater adhesive strength in the coatings. The quality of the coatings was confirmed by experiments using the optimal parameter settings.

\section{Experiments}

This study aims to analyze the residual stresses present in a cold-forged part after heat treatments. It is assumed that there will be a superposition of residual stresses in the final product, combining the residual stresses generated during cold forming with those induced by heat treatment. It is expected that the results will enable designers to choose manufacturing and heat treatment processes that will increase the mechanical strength of a part.

In experiments, residual stresses were evaluated using a microindentation test technique. A sample of AISI 1045 steel was forged and then submitted to different heat treatments. Microhardness tests were performed on the sample to determine the effects of cold forming and heat treatments.

2.1. Materials. A wedge-shaped tool was manufactured using AISI H13 steel and then quenched and tempered to RC 52 hardness. The wedge angle was $75^{\circ}$, and the wedge base length was $5 \mathrm{~mm}$. A support for the samples was made using the same material and submitted to the same heat treatment.

Samples of AISI 1045 steel were forged using this tool. The samples were forged into the shape of a half cylinder with a radius of $12.5 \mathrm{~mm}$ and a thickness of $10 \mathrm{~mm}$. This steel was chosen because it can accept a wide range of heat treatments. A tensile test was performed to determine its mechanical properties. Its ultimate tensile strength was $572 \mathrm{MPa}$, and its yield tensile strength was $489 \mathrm{MPa}$. Its chemical composition is shown in Table 1.

2.2. Methods. The experiments were performed using a factorial design with two influence factors. The first factor was the material condition (A), with six levels: forged and quenched (A1); forged, quenched, and tempered (A2); forged as-received (A3); forged and normalized (A4); unforged asreceived (A5); and forged and annealed (A6). The second factor was the measurement position $(\mathrm{P})$, with three levels: the left edge of the wedge impression (P1), the center of 
TABLE 1: Chemical composition of the AISI 1045 steel samples.

\begin{tabular}{lccccccc}
\hline$\% \mathrm{C}$ & $\% \mathrm{Mn}$ & $\% \mathrm{P}$ & $\% \mathrm{Cr}$ & $\% \mathrm{~S}$ & $\% \mathrm{Si}$ & $\% \mathrm{Ni}$ & 0.08 \\
\hline 0.43 & 0.79 & 0.03 & 0.03 & 0.02 & 0.24 & 0.03 \\
\hline
\end{tabular}

TABLE 2: Design of the experiments.

\begin{tabular}{ccccccccccc}
\hline & \multicolumn{1}{c}{} & \multicolumn{1}{c}{ P1 } & \multicolumn{9}{c}{ P2 } & \multicolumn{3}{c}{ P3 } \\
& & Rep. 1 & Rep. 2 & Rep. 3 & Rep. 1 & Rep. 2 & Rep. 3 & Rep. 1 & Rep. 2 & Rep. 3 \\
\hline \multirow{6}{*}{ Condition } & A1 & X & X & X & X & X & X & X & X & X \\
& A2 & X & X & X & X & X & X & X & X & X \\
& A3 & X & X & X & X & X & X & X & X & X \\
& A4 & X & X & X & X & X & X & X & X & X \\
& A5 & X & X & X & X & X & X & X & X & X \\
& A6 & X & X & X & X & X & X & X & X & X \\
\hline
\end{tabular}

the wedge impression (P2), and the right edge of the wedge impression (P3).

The response variable was the Vickers microhardness. Vickers microhardness was used because the breadth of its scale enabled the evaluation of the wide range of hardness values expected between the as-received condition and the quenched condition. The load used in the tests of the quenched, quenched and tempered, normalized, and forged as-received specimens was $500 \mathrm{~N}$. The load used in the tests of the annealed and unforged as-received specimens was $294 \mathrm{~N}$. These loads were required to obtain precise results.

Finite element analysis was used to determine the regions in which the sample would be most sensitive to the residual stresses due to forging. The finite element analysis was performed in Abaqus software using 3000 solid parametric 8node elements. An elastoplastic model was used to represent the stress-strain curve of the material.

The heat treatments were performed as follows. For quenching, the material was heated to $800^{\circ} \mathrm{C}$, maintained at this temperature for 25 minutes, and then cooled in water with a circular motion. For annealing, the material was heated to $800^{\circ} \mathrm{C}$, maintained at this temperature for 25 minutes, and then cooled in a furnace. Normalization was performed by raising the material temperature to $910^{\circ} \mathrm{C}$, maintaining this temperature for 25 minutes, and then cooling the material in calm air. For tempering, the material was heated to $400^{\circ} \mathrm{C}$, maintained at this temperature for 30 minutes, and then cooled in calm air.

A factorial design was used for the experiments. In each condition, the measurement was repeated three times.

Analysis of variance was used to interpret the results, with a significance level of $5 \%$. The design of the experiments is presented in Table 2.

\section{Results}

Figure 1 presents the results of the numerical simulation. Care was taken when the wedge tool was retrieved after forging was completed; so the effective stresses shown in the figure represent the residual stresses due to the forging operation.

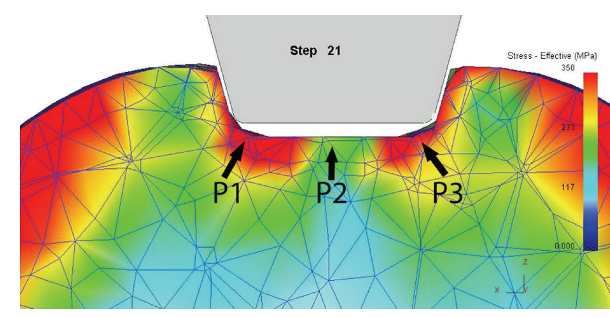

FIGURE 1: Numerical simulation showing von Mises equivalent strain.

As shown in Figure 1 the highest strain occurs near the edges of the wedge. It can be observed that the stresses near the center of the wedge are of significantly lower intensity. The measurement positions, $\mathrm{P} 1, \mathrm{P} 2$, and $\mathrm{P} 3$, are shown in the figure. The indentation tests were performed at these three points to measure the microhardness.

Figure 2 shows the average hardness from the three measurements taken at each position in each condition. Taking as a reference the unforged as-received condition (A5), it is clear that the heat treatments increased the hardness in all cases except condition A6. If the forged as-received condition (A3) is used as the reference, then the quenching treatment and the quenching and tempering treatment increased the hardness of the specimen, whereas the annealing and normalizing treatments reduced the hardness. The figure also shows that there was no significant difference in hardness between the three measurement positions for each treatment.

The annealing treatment reduced the hardness to a level that was less than the hardness measured in the unforged asreceived material.

The normalization treatment also reduced the residual stress relative to the stress measured in the forged specimen, but the stress remained higher than in the unforged asreceived material.

The quenching treatment and the quenching and tempering treatment increased the residual stress relative to the forged as-received specimen, and these stresses were compressive. 
TABLE 3: Vickers hardness (VH) results.

\begin{tabular}{|c|c|c|c|}
\hline \multirow{2}{*}{ Conditions } & \multicolumn{3}{|c|}{ Position } \\
\hline & P1 & $\mathrm{P} 2$ & P3 \\
\hline \multirow{3}{*}{ A1: forged and quenched } & 724 & 699 & 662 \\
\hline & 678 & 672 & 672 \\
\hline & 678 & 682 & 695 \\
\hline \multirow{3}{*}{ A2: forged, quenched, and tempered } & 460 & 452 & 477 \\
\hline & 475 & 471 & 485 \\
\hline & 481 & 487 & 471 \\
\hline \multirow{3}{*}{ A3: forged as-received } & 247 & 253 & 262 \\
\hline & 264 & 269 & 272 \\
\hline & 268 & 262 & 263 \\
\hline \multirow{3}{*}{ A4: forged and normalized } & 206 & 206 & 206 \\
\hline & 206 & 205 & 206 \\
\hline & 198 & 200 & 204 \\
\hline \multirow{3}{*}{ A5: unforged as-received } & 184 & 180 & 180 \\
\hline & 177 & 179 & 178 \\
\hline & 176 & 180 & 185 \\
\hline \multirow{3}{*}{ A6: forged and annealed } & 158 & 156 & 160 \\
\hline & 161 & 156 & 156 \\
\hline & 165 & 161 & 161 \\
\hline
\end{tabular}

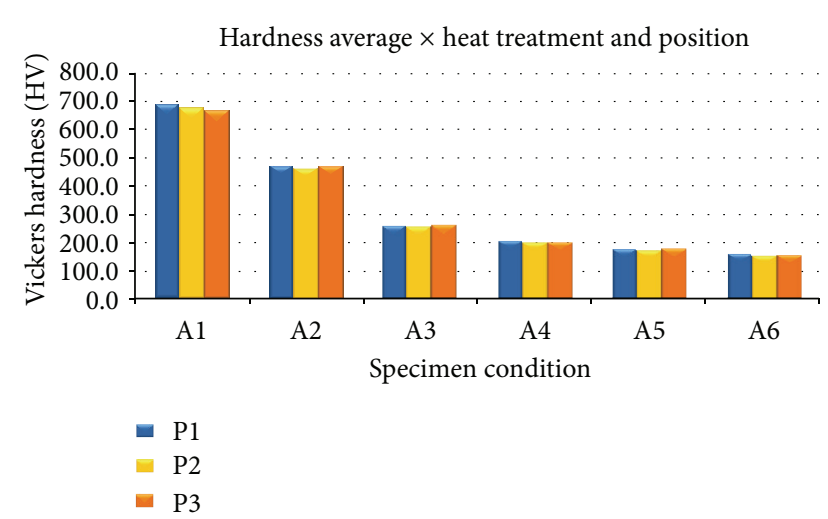

FIGURE 2: Average Vickers hardness as a function of the heat treatment and measurement position.

The results of the experiments are shown in Table 3, and a graph of the average hardness for each position is shown in Figure 2.

Table 4 presents the analysis of variance results. In the table, SST is the sum of squares for all measurements, SS (A) is the sum of squares for all treatments (i.e., all conditions), SS $(\mathrm{P})$ is the sum of squares for all positions, $\mathrm{SS}(\mathrm{A} \times \mathrm{P})$ is the sum of squares for all interactions, and $\mathrm{SS}_{\mathrm{err}}$ is the sum of squares of the errors for all measures. GL is the degree of freedom for each element. MSS is the average sum of squares. $F$ is the Fisher statistic used to evaluate the variance of an element. $F$ calc is the observed Fisher statistic, and $F$ tab is the expected value at the $95 \%$ confidence level. If the expected variance $(F$ calc) is less than the observed variance $(F$ tab), then the treatment significantly influenced the result and the treatment averages were different.
The analysis of variance results show that both the thermal and mechanical treatments influenced the result because there was a statistically significant difference. Therefore, the average hardness was different for the different conditions (i.e., the thermal and mechanical treatments).

A significant effect of the measurement position was not found. Therefore, the hardness at positions P1, P2, and P3 was statistically equal. The analysis of variance also showed no significant interaction between the treatment and the measurement position.

\section{Discussion}

The unforged as-received condition (A5) is taken as the reference material. The material used was a rolled steel. Therefore, residual stress was introduced by the previous rolling process. Rolling introduces compressive residual stress, as was verified by Wronski et al. [7] in their study of the effect of rolling on the residual stress in FCC and BCC metals.

An increase in hardness relative to the reference material indicates the presence of compressive residual stresses, whereas tensile residual stresses are indicated by a reduction in hardness. Consequently, the cold forging condition (A3) introduced greater compressive residual stress at the measurement points (P1, P2, and P3). This is consistent with previous results in the literature, such as the work of Martins et al. [4] previously mentioned. Compressive stress is beneficial for parts that are subject to cyclical loads because it helps to prevent the initiation and propagation of cracks.

The specimen that was annealed after forging (condition A6) demonstrated an undesirable effect because its hardness was reduced to less than the hardness measured in the reference material. Any residual stress in the reference material 
TABLE 4: Analysis of variance.

\begin{tabular}{|c|c|c|c|c|c|c|}
\hline & SS & GL & MSS & $F$ calc & $F$ tab & Analysis \\
\hline SST & 1969766 & 53 & & & & \\
\hline SS (A) & 1965219 & 5 & 393043.8 & 3002.881 & 2.533 & Significant \\
\hline $\mathrm{SS}(\mathrm{P})$ & 37.814 & 3 & 12.60 & 0.096 & 2.922 & Not significant \\
\hline $\mathrm{SS}(\mathrm{A} \times \mathrm{P})$ & 582.407 & 15 & 38.82 & 0.296 & 2.015 & Not significant \\
\hline $\mathrm{SS}_{\mathrm{err}}$ & 3926.667 & 30 & 130.88 & & & \\
\hline
\end{tabular}

would have been eliminated by annealing. Consequently, tensile residual stresses would be superimposed in the specimen, reducing the compressive residual stresses resulting from forging or producing completely tensile stresses. This effect is well established in the literature, as in the work of Fu and Jiang [13]. In their work, they observed stress relaxation in the surface layer of shot-peened steel after annealing.

The stresses introduced by forging were relieved, but not eliminated, when the normalizing heat treatment was used (condition A4). This can be expected because normalization is a stress-relieving heat treatment. For example, Wei and Lu [14] observed a reduction in tensile strength after single and multiple normalization steps in welded steel.

Quenching after forging (A1) increased the hardness more than any other treatment and consequently increased the compressive residual stress. This was previously observed by Camurri et al. [2], as cited in the Introduction. As expected, the specimen that was forged, quenched, and tempered (condition A2) showed greater relief of residual stress than the specimen that was forged and quenched. Like normalization, tempering is a stress-relieving heat treatment.

\section{Conclusions}

Residual stresses can be beneficial or not, depending on the intended use of the mechanical part. For parts exposed to cyclical loads, the presence of compressive residual stresses is desirable. After cold forging AISI 1045 steel samples and applying heat treatments, we can conclude the following.

(1) Cold forging introduced compressive residual stresses in the surface region studied, which would increase the strength of a cyclically loaded part.

(2) The quenching treatment and the quenching and tempering treatment increased the compressive residual stresses in the forged specimen, amplifying the compressive residual stresses generated during forging.

(3) The normalization treatment reduced the residual stresses in the forged specimen. Because compressive residual stresses are desirable, normalization worsens the results obtained by forging.

(4) The annealing treatment reduced the residual stresses to a level lower than in the as-received material. All compressive residual stresses introduced by forging were relieved.

(5) Three measurement points were chosen in the region of increased plastic strain to study the residual stress.
However, no statistically significant differences were observed between the residual stress measurements from the three points.

As a general conclusion, focusing on the compressive residual stress, annealing and normalization treatments are not recommended for a forged part. Only quenching or quenching followed by tempering was shown to increase the compressive residual stress in cold-forged parts.

\section{Conflict of Interests}

The authors declare that there is no conflict of interests regarding the publication of this paper.

\section{Acknowledgment}

The authors wish to thank FAPEMIG for financial support for the research.

\section{References}

[1] M. P. Mungi, S. D. Rasane, and P. M. Dixit, "Residual stresses in cold axisymmetric forging," Journal of Materials Processing Technology, vol. 142, no. 1, pp. 256-266, 2003.

[2] C. Camurri, C. Carrasco, and J. Dille, "Residual stress during heat treatment of steel grinding balls," Journal of Materials Processing Technology, vol. 208, no. 1-3, pp. 450-456, 2008.

[3] D. A. Lados, D. Apelian, and L. Wang, "Minimization of residual stress in heat-treated $\mathrm{Al}-\mathrm{Si}-\mathrm{Mg}$ cast alloys using uphill quenching: mechanisms and effects on static and dynamic properties," Materials Science and Engineering A, vol. 527, no. 13-14, pp. 3159-3165, 2010.

[4] J. A. Martins, L. P. Cardoso, J. A. Fraymann, and S. T. Button, "Analyses of residual stresses on stamped valves by X-ray diffraction and finite elements method," Journal of Materials Processing Technology, vol. 179, no. 1-3, pp. 30-35, 2006.

[5] Z. T. Tang, Z. Q. Liu, Y. Z. Pan, Y. Wan, and X. Ai, "The influence of tool flank wear on residual stresses induced by milling aluminum alloy," Journal of Materials Processing Technology, vol. 209, no. 9, pp. 4502-4508, 2009.

[6] L. L. Meisner, A. I. Lotkov, M. G. Ostapenko, and E. Y. Gudimova, "X-ray diffraction study of residual elastic stress and microstructure of near-surface layers in nickel-titanium alloy irradiated with low-energy high-current electron beams," Applied Surface Science, vol. 280, pp. 398-404, 2013.

[7] S. Wronski, M. Wrobel, A. Baczmanski, and K. Wierzbanowski, "Effects of cross-rolling on residual stress, texture and plastic anisotropy in f.c.c. and b.c.c. metals," Materials Characterization, vol. 77, pp. 116-126, 2013. 
[8] M. Bocciarelli and G. Maier, "Indentation and imprint mapping method for identification of residual stresses," Computational Materials Science, vol. 39, no. 2, pp. 381-392, 2007.

[9] D. A. Tanner and J. S. Robinson, "Reducing residual stress in 2014 aluminium alloy die forgings," Materials and Design, vol. 29, no. 7, pp. 1489-1496, 2008.

[10] M. Koç, J. Culp, and T. Altan, "Prediction of residual stresses in quenched aluminum blocks and their reduction through cold working processes," Journal of Materials Processing Technology, vol. 174, no. 1-3, pp. 342-354, 2006.

[11] J. Grum and J. M. Slabe, "The use of factorial design and response surface methodology for fast determination of optimal heat treatment conditions of different Ni-Co-Mo surfaced layers," Journal of Materials Processing Technology, vol. 155-156, no. 1-3, pp. 2026-2032, 2004.

[12] J. Grum and Z. Bergant, "The optimisation of powder flamespraying parameters using a Taguchi method," International Journal of Microstructure and Materials Properties, vol. 3, no. 45, pp. 682-700, 2008.

[13] P. Fu and C. Jiang, "Residual stress relaxation and microstructural development of the surface layer of $18 \mathrm{CrNiMo7}-6$ steel after shot peening during isothermal annealing," Materials \& Design, vol. 56, pp. 1034-1038, 2014.

[14] S. Wei and S. Lu, "Effects of multiple normalizing processes on the microstructure and mechanical properties of low carbon steel weld metal with and without Nb," Materials and Design, vol. 35, pp. 43-54, 2012. 

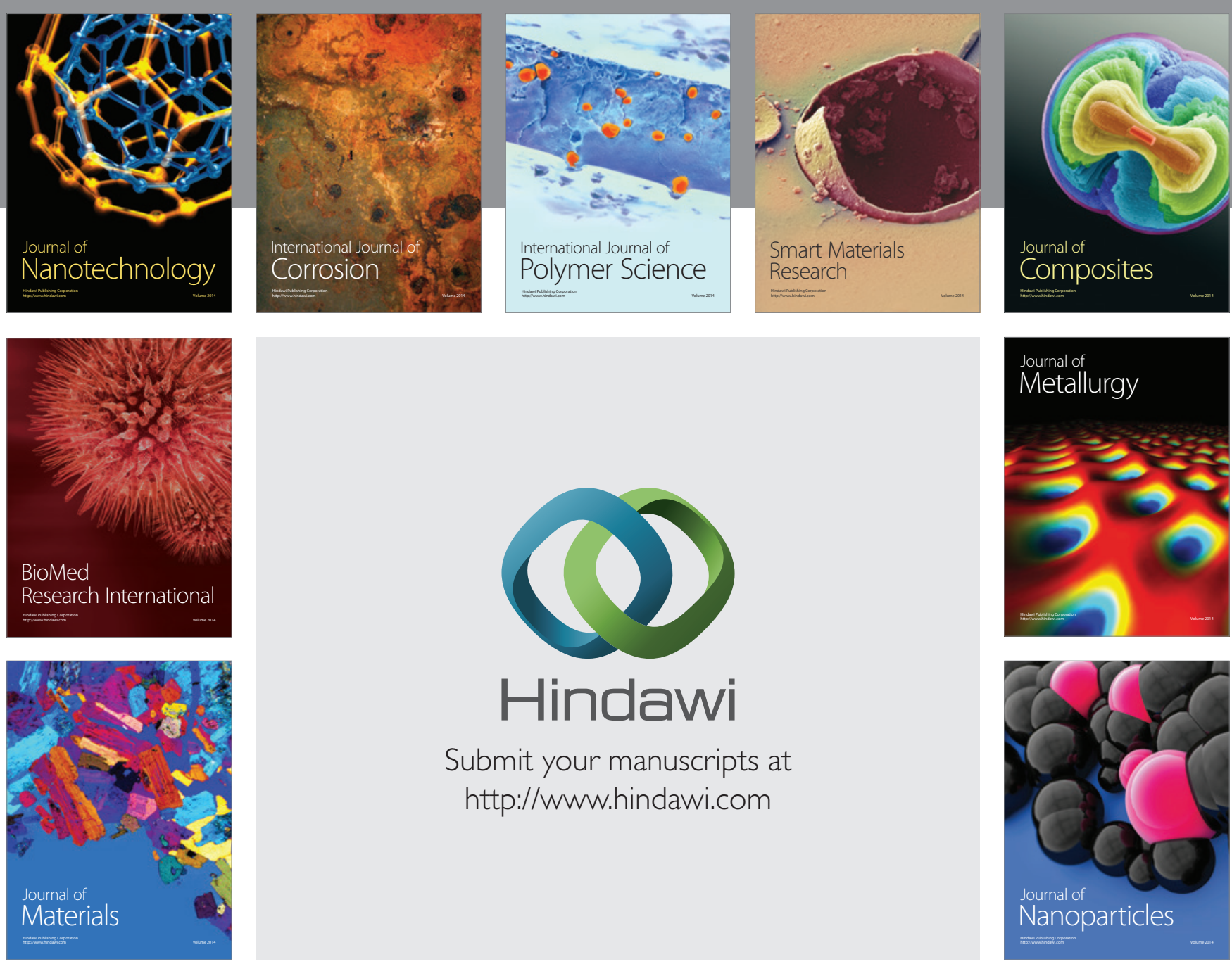

Submit your manuscripts at http://www.hindawi.com
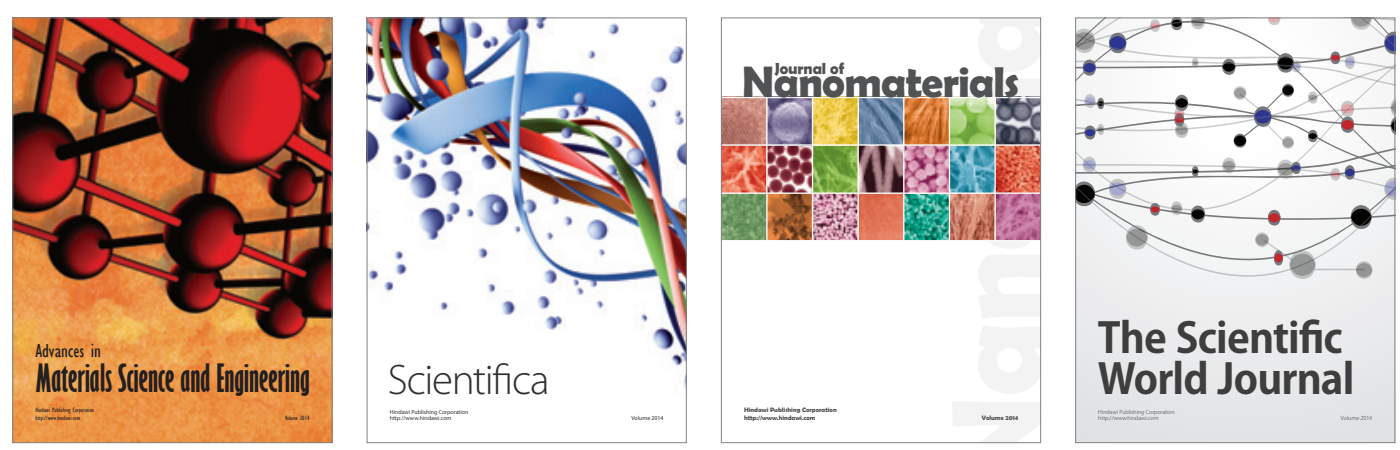

\section{The Scientific World Journal}
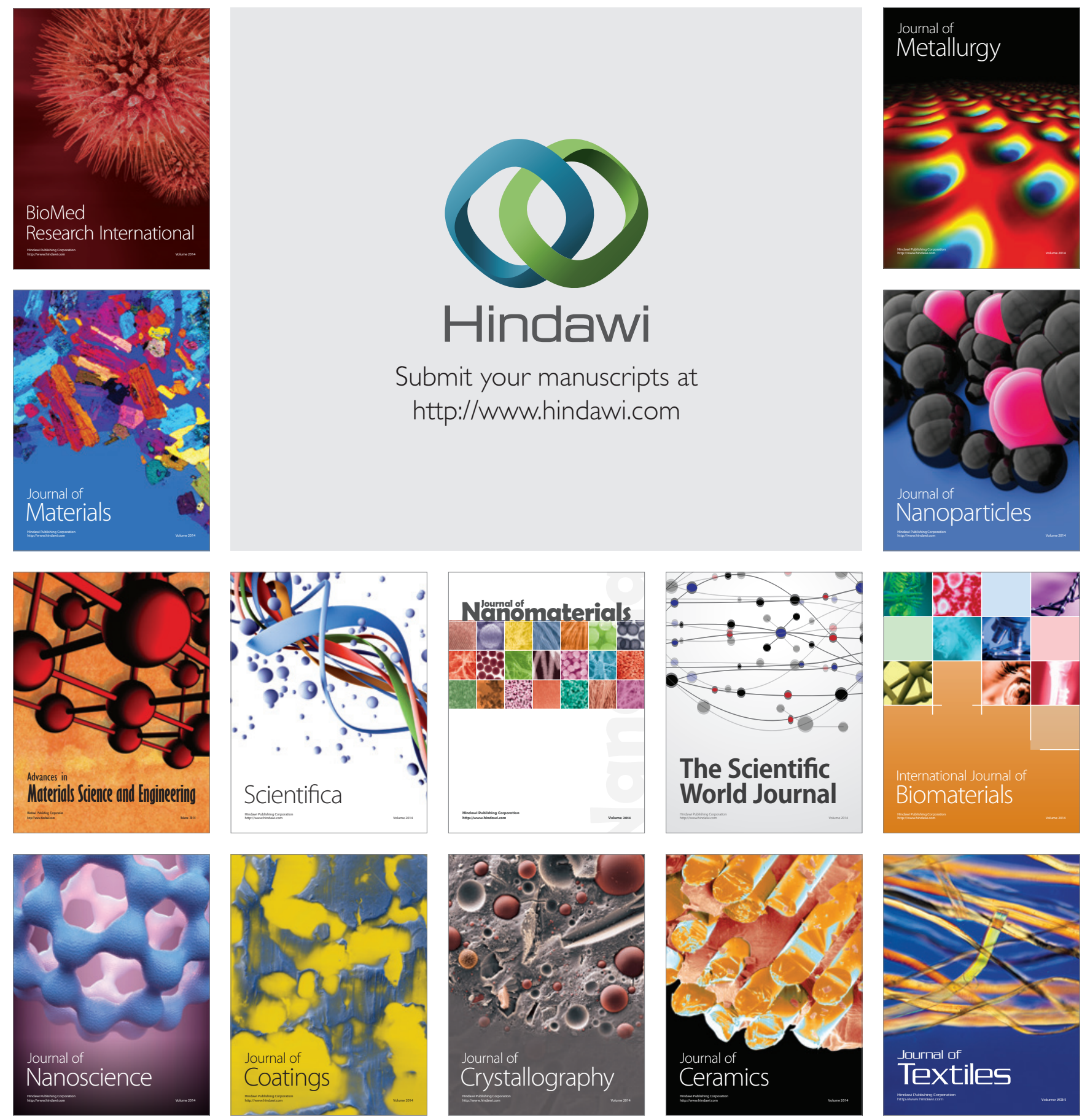